\title{
Transverse Vibration of Axially Moving Functionally Graded Materials Based on Timoshenko Beam Theory
}

\author{
Suihan Sui, Ling Chen, Cheng Li, and Xinpei Liu \\ School of Urban Rail Transportation, Soochow University, Suzhou 215006, China \\ Correspondence should be addressed to Cheng Li; licheng@suda.edu.cn
}

Received 16 August 2014; Accepted 18 October 2014

Academic Editor: Kim M. Liew

Copyright ( 2015 Suihan Sui et al. This is an open access article distributed under the Creative Commons Attribution License, which permits unrestricted use, distribution, and reproduction in any medium, provided the original work is properly cited.

\begin{abstract}
The transverse free vibration of an axially moving beam made of functionally graded materials (FGM) is investigated using a Timoshenko beam theory. Natural frequencies, vibration modes, and critical speeds of such axially moving systems are determined and discussed in detail. The material properties are assumed to vary continuously through the thickness of the beam according to a power law distribution. Hamilton's principle is employed to derive the governing equation and a complex mode approach is utilized to obtain the transverse dynamical behaviors including the vibration modes and natural frequencies. Effects of the axially moving speed and the power-law exponent on the dynamic responses are examined. Some numerical examples are presented to reveal the differences of natural frequencies for Timoshenko beam model and Euler beam model. Moreover, the critical speed is determined numerically to indicate its variation with respect to the power-law exponent, axial initial stress, and length to thickness ratio.
\end{abstract}

\section{Introduction}

The axially moving systems are extensively applied in machinery, electronics, and some other related fields. Many engineering devices such as band-saw blade, power transmission belts, and crane hoist cables can be modeled as axially moving systems. Transverse vibration of axially moving systems may induce some disadvantageous effects. For example, the transverse vibration of power transmission belts causes noise and accelerated wear of the belt; the vibration of the blade in band saws leads to poor cutting quality. Therefore, research of the transverse vibration of axially moving beams is indispensable, which has important engineering significance in controlling and optimizing the transverse dynamics. At present, the axially moving beam structures have been widely studied, of which most literatures are based on EulerBernoulli beam model. Öz [1] computed natural frequencies of an axially moving beam in contact with a small stationary mass under pinned-pinned or clamped-clamped boundary conditions. Chen et al. [2] studied the dynamic stability of an axially accelerating viscoelastic beam and analyzed the effects of the dynamic viscosity, the mean axial speed, and the tension on the stability conditions. Chen and Yang [3] developed two nonlinear models for transverse vibration of an axially accelerating viscoelastic beam and applied the method of multiple scales to compare the corresponding steady-state responses and their stability. Chen and Yang [4] presented the first two mode frequencies of axially moving elastic and viscoelastic beams under simple supports with torsion springs. Lee and Jang [5] studied the effects of the continuously incoming and outgoing semi-infinite beam parts on the dynamic characteristics and stability of an axially moving beam by using the spectral element method. Lin and Qiao [6] determined some numerical results for natural frequency of an axially moving beam in fluid based on a differential quadrature method. Ghayesh et al. [7] developed an approximate analytical solution for nonlinear dynamic responses of a simply supported Kelvin-Voigt viscoelastic beam with an attached heavy intraspan mass. Lv et al. [8] investigated natural frequency, bifurcation, and stability of transverse vibration of axially accelerating moving viscoelastic sandwich beams with time-dependent axial tension.

All the cases aforementioned are in the framework of Euler-Bernoulli beam model. However, it does not contain the information about shear stress and moment of inertia in Euler-Bernoulli beam model. Consequently, the Timoshenko 
beam model has received more attention in modeling the axially moving structures in recent years. Lee et al. [9] formulated the spectral element model for the transverse vibration of an axially moving Timoshenko beam subjected to a constant axial tension and verify its high accuracy by comparing with the solutions by other methods. Tang et al. [10] analyzed the parametric resonance of axially moving Timoshenko beams with time-dependent speed. Ghayesh and Balar [11] presented nonlinear vibration and stability analysis of an axially moving Timoshenko beam for two dynamic models and employed the multiple scales method to obtain the mode shape equations, natural frequencies, and steady-state responses of the system. Li et al. [12] studied the nonlinear free transverse vibrations of the axially moving Timoshenko beam with constant speed. Ghayesh and Amabili [13] investigated the nonlinear forced vibrations and stability of an axially moving Timoshenko beam with an intraspan spring-support. All the literatures using axially moving Timoshenko beam model receive more accurate results and it is applicable to the stubby axially moving structures.

In engineering practices, the axially moving beam may be made by FGM. The present study is concerned with the axially moving FGM Timoshenko beam. In the related literatures, most are focused on the mechanical properties of FGM without axial motion but the studies of axially moving FGM Timoshenko beam are very few. Ding et al. [14] derived a series of analytical solutions for anisotropic FGM beams with various end conditions using an Airy stress function in the generalized polynomial form. Kang and Li [15] investigated the mechanical behaviors of a nonlinear FGM cantilever beam subjected to an end force by using large and small deformation theories. Zhou et al. [16] studied the mechanical responses of a functionally graded cantilever beam by use of two kinds of particle with different properties based on discrete element method. Şimşek [17] investigated the forced vibration of a functionally graded beam under a moving mass by using Euler-Bernoulli, Timoshenko, and the thirdorder shear deformation beam theories. Alshorbagy et al. [18] studied the free vibration of a functionally graded beam by finite element method with material graduation axially or transversally through the thickness. Ke et al. [19] investigated nonlinear free vibration of size-dependent functionally graded microbeams based on the modified couple stress theory and von Kármán geometric nonlinearity. Şimşek et al. [20] analytically examined static bending of functionally graded microbeams based on the modified couple stress theory and Euler-Bernoulli and Timoshenko beam theories, respectively.

Considering the wide application of axially moving structures and the excellent characteristics of FGM, the investigation of transverse vibration of axially moving beams made of FGM is of great significance both in theoretical study and engineering application. In this paper, the transverse vibration of an axially moving, initially tensioned beam made of FGM is investigated. The Timoshenko beam model is utilized and the complex mode approach is performed to obtain the natural frequencies and the modal functions. With the numerical example for boundary condition of simply

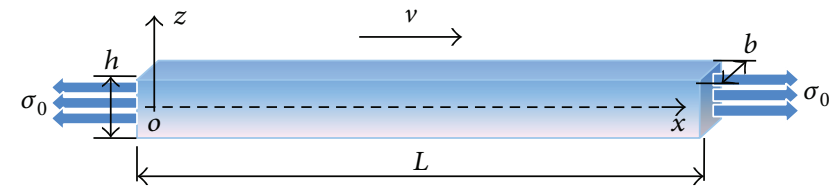

FIGURE 1: Schematics of an axially moving FGM beam.

supported on both ends, the effects of power-law exponent, axial speed, and initial stress to the natural frequencies are analyzed and discussed in detail. Finally, the critical speed is determined to show its variation with different power-law exponent, axial initial stress, and length to thickness ratio.

\section{Physical Model}

For an axially moving FGM beam as shown in Figure 1, the beam travels at a speed $v$ between two boundaries separated by distance $L$ under an applied axial initial stress $\sigma_{0}$. The cross section is a rectangle of thickness $h$ and width $b$. The coordinate system $(O x z)$ is defined on the middle plane of the beam. Note that the $x$-axis is taken along the middle plane and the $z$-axis in the thickness direction.

The elastic modulus $E\left(\mathrm{~N} / \mathrm{m}^{2}\right)$ and density $\rho\left(\mathrm{kg} / \mathrm{m}^{3}\right)$ of the beam are assumed to vary through the thickness following a simple power-law distribution. They can be described by

$$
\begin{array}{r}
E(z)=\left(E_{c}-E_{m}\right)\left(\frac{z}{h}+\frac{1}{2}\right)^{k}+E_{m}, \\
\rho(z)=\left(\rho_{c}-\rho_{m}\right)\left(\frac{z}{h}+\frac{1}{2}\right)^{k}+\rho_{m}, \\
-\frac{h}{2} \leq z \leq \frac{h}{2},
\end{array}
$$

where $k$ stands for the power-law exponent. As the FGM beam is assumed to be made of pure Alumina ceramics and pure steel metal, subscripts $c$ and $m$ refer to the ceramic $\left(E_{c}=390 \mathrm{GPa}, \rho_{c}=3960 \mathrm{~kg} / \mathrm{m}^{3}\right)$ and metal $\left(E_{m}=210 \mathrm{GPa}\right.$, $\rho_{m}=7800 \mathrm{~kg} / \mathrm{m}^{3}$ ), respectively.

\section{Governing Equation and Theoretical Formulation}

Based on the Timoshenko beam theory, the total transverse deflection and the angle of rotation due to bending are denoted by $w(x, t)$ and $\psi(x, t)$, respectively. The kinetic energy $T$ and potential energies $V$ are given by

$$
\begin{gathered}
T=\frac{1}{2} \int_{0}^{L}\left\{\rho_{T 0}\left[v^{2}+\left(\frac{\partial w}{\partial t}+v \frac{\partial w}{\partial x}\right)^{2}\right]\right. \\
\left.+\rho_{T 2}\left(\frac{\partial \psi}{\partial t}+v \frac{\partial \psi}{\partial x}\right)^{2}\right\} d x, \\
V=\frac{1}{2} \int_{0}^{L}\left\{(E I)_{\mathrm{eq}}\left(\frac{\partial \psi}{\partial x}\right)^{2}+\kappa G_{T}\left(\frac{\partial w}{\partial x}-\psi\right)^{2}\right. \\
\left.+\sigma_{0} A\left(\frac{\partial w}{\partial x}\right)^{2}\right\} d x,
\end{gathered}
$$


where

$$
\begin{gathered}
\rho_{T 0}=\int_{A} \rho(z) d A, \quad \rho_{T 2}=\int_{A} \rho(z) z^{2} d A \\
G_{T}=\int_{A} G(z) d A, \quad(E I)_{\mathrm{eq}}=\int_{A} E(z) z^{2} d A, \\
G(z)=\frac{E(z)}{2(1+\mu)},
\end{gathered}
$$

in which $\mu$ is the Poisson's ratio and $\kappa$ is the shear correction factor.

Substitute (2) into the extended Hamilton's principle

$$
\int_{t_{1}}^{t_{2}}(\delta T-\delta V) d t=0
$$

The detail is shown in Appendix A from which the equations of motion for the axially moving FGM Timoshenko beam can be derived as

$$
\begin{aligned}
& \kappa G_{T}\left(\frac{\partial^{2} w}{\partial x^{2}}-\frac{\partial \psi}{\partial x}\right)-\rho_{T 0}\left(\frac{\partial^{2} w}{\partial t^{2}}+2 v \frac{\partial^{2} w}{\partial t \partial x}+v^{2} \frac{\partial^{2} w}{\partial x^{2}}\right) \\
& \quad+\sigma_{0} A \frac{\partial^{2} w}{\partial x^{2}}=0, \\
& (E I)_{\mathrm{eq}} \frac{\partial^{2} \psi}{\partial x^{2}}-\rho_{T 2}\left(\frac{\partial^{2} \psi}{\partial t^{2}}+2 v \frac{\partial^{2} \psi}{\partial t \partial x}+v^{2} \frac{\partial^{2} \psi}{\partial x^{2}}\right) \\
& \quad+\kappa G_{T}\left(\frac{\partial w}{\partial x}-\psi\right)=0 .
\end{aligned}
$$

Decoupling (5) and (6) yields the governing equation for the transverse vibration of such axially moving FGM Timoshenko beams

$$
\begin{aligned}
(1- & \left.a_{2} v^{2}\right)\left(1+a_{4}-a_{1} v^{2}\right) \frac{\partial^{4} w}{\partial x^{4}} \\
& -2 v\left(a_{1}+a_{2}+a_{2} a_{4}-2 a_{1} a_{2} v^{2}\right) \frac{\partial^{4} w}{\partial t \partial x^{3}} \\
& +a_{3}\left(a_{1} v^{2}-a_{4}\right) \frac{\partial^{2} w}{\partial x^{2}}-\left(a_{1}+a_{2}+a_{2} a_{4}-6 a_{1} a_{2} v^{2}\right) \\
& \times \frac{\partial^{4} w}{\partial t^{2} \partial x^{2}}+4 a_{1} a_{2} v \frac{\partial^{4} w}{\partial t^{3} \partial x}+2 a_{1} a_{3} v \frac{\partial^{2} w}{\partial t \partial x} \\
& +a_{1} a_{3} \frac{\partial^{2} w}{\partial t^{2}}+a_{1} a_{2} \frac{\partial^{2} w}{\partial t^{4}}=0,
\end{aligned}
$$

where

$$
\begin{array}{ll}
a_{1}=\frac{\rho_{T 0}}{\kappa G_{T}}, & a_{2}=\frac{\rho_{T 2}}{(E I)_{\mathrm{eq}}}, \\
a_{3}=\frac{\kappa G_{T}}{(E I)_{\mathrm{eq}}}, & a_{4}=\frac{\sigma_{0} A}{\kappa G_{T}} .
\end{array}
$$

\section{Case Studies}

4.1. Natural Frequencies and Mode Function. The boundary conditions for the simple supports at both ends are given by

$$
\begin{aligned}
w(0, t) & =0 ; & & w(L, t)=0 ; \\
\frac{\partial^{2} w(0, t)}{\partial x^{2}} & =0 ; & & \frac{\partial^{2} w(L, t)}{\partial x^{2}}=0 .
\end{aligned}
$$

The solution to (7) can be assumed as

$$
w(x, t)=\varphi_{n}(x) e^{i \omega_{n} t}+\bar{\varphi}_{n}(x) e^{-i \omega_{n} t},
$$

where $\varphi_{n}$ and $\omega_{n}$ denote the $n$th mode function and natural frequency, respectively. $\bar{\varphi}_{n}$ represents the complex conjugate of $\varphi_{n}$. Substitution of (10) into (7) and (9) leads to

$$
\begin{gathered}
\left(1-a_{2} v^{2}\right)\left(1+a_{4}-a_{1} v^{2}\right) \varphi_{n}^{(4)} \\
-2 i \omega_{n} v\left(a_{1}+a_{2}+a_{2} a_{4}-2 a_{1} a_{2} v^{2}\right) \varphi_{n}^{(3)} \\
+\left[a_{3}\left(a_{1} v^{2}-a_{4}\right)+\omega_{n}^{2}\left(a_{1}+a_{2}+a_{2} a_{4}-6 a_{1} a_{2} v^{2}\right)\right] \varphi_{n}^{\prime \prime} \\
-2 i a_{1} v \omega_{n}\left(2 a_{2} \omega_{n}^{2}-a_{3}\right) \varphi_{n}^{\prime}-a_{1} \omega_{n}^{2}\left(a_{3}-a_{2} \omega_{n}^{2}\right) \varphi_{n}=0 \\
\varphi_{n}(0)=0 ; \quad \varphi_{n}(L)=0 ; \\
\varphi_{n}^{\prime \prime}(0)=0 ; \quad \varphi_{n}^{\prime \prime}(L)=0,
\end{gathered}
$$

where $\varphi_{n}^{(4)}, \varphi_{n}^{(3)}, \varphi_{n}^{\prime \prime}$, and $\varphi_{n}^{\prime}$ denote the derivative with respect to coordinate $x$. The solution to ordinary differential equation (11) can be expressed by

$$
\varphi_{n}(x)=C_{1 n} e^{\beta_{1 n} x}+C_{2 n} e^{\beta_{2 n} x}+C_{3 n} e^{\beta_{3 n} x}+C_{4 n} e^{\beta_{4 n} x},
$$

where $C_{1 n} \sim C_{4 n}$ are four unknown constants and $\beta_{1 n} \sim \beta_{4 n}$ are four complex eigenvalues of (11). Substituting (13) into (12) yields

$$
\begin{gathered}
C_{1 n}+C_{2 n}+C_{3 n}+C_{4 n}=0, \\
C_{1 n} e^{\beta_{1 n}}+C_{2 n} e^{\beta_{2 n}}+C_{3 n} e^{\beta_{3 n}}+C_{4 n} e^{\beta_{4 n}}=0, \\
C_{1 n} \beta_{1 n}^{2}+C_{2 n} \beta_{2 n}^{2}+C_{3 n} \beta_{3 n}^{2}+C_{4 n} \beta_{4 n}^{2}=0 \\
C_{1 n} \beta_{1 n}^{2} e^{\beta_{1 n}}+C_{2 n} \beta_{2 n}^{2} e^{\beta_{2 n}}+C_{3 n} \beta_{3 n}^{2} e^{\beta_{3 n}}+C_{4 n} \beta_{4 n}^{2} e^{\beta_{4 n}}=0 .
\end{gathered}
$$

Rewrite (14a), (14b), (14c), and (14d) in the form of a matrix as

$$
\left(\begin{array}{cccc}
1 & 1 & 1 & 1 \\
e^{\beta_{1 n}} & e^{\beta_{2 n}} & e^{\beta_{3 n}} & e^{\beta_{4 n}} \\
\beta_{1 n}^{2} & \beta_{2 n}^{2} & \beta_{3 n}^{2} & \beta_{4 n}^{2} \\
\beta_{1 n}^{2} e^{\beta_{1 n}} & \beta_{2 n}^{2} e^{\beta_{2 n}} & \beta_{3 n}^{2} e^{\beta_{3 n}} & \beta_{4 n}^{2} e^{\beta_{4 n}}
\end{array}\right)\left(\begin{array}{c}
C_{1 n} \\
C_{2 n} \\
C_{3 n} \\
C_{4 n}
\end{array}\right)=0 .
$$

For the nontrivial solution of (15), the determinant of the coefficient matrix must be zero. 


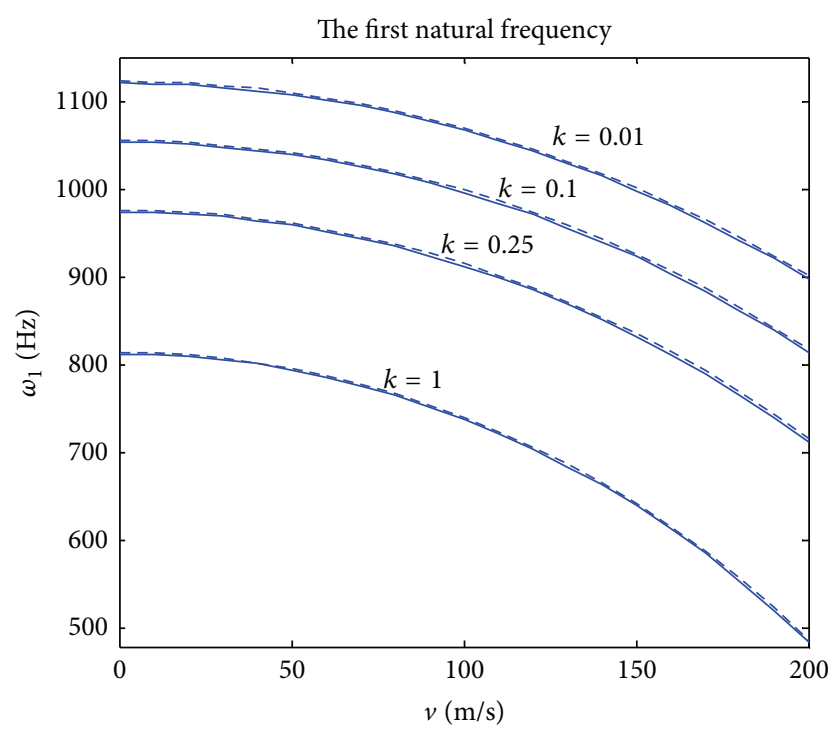

(a)

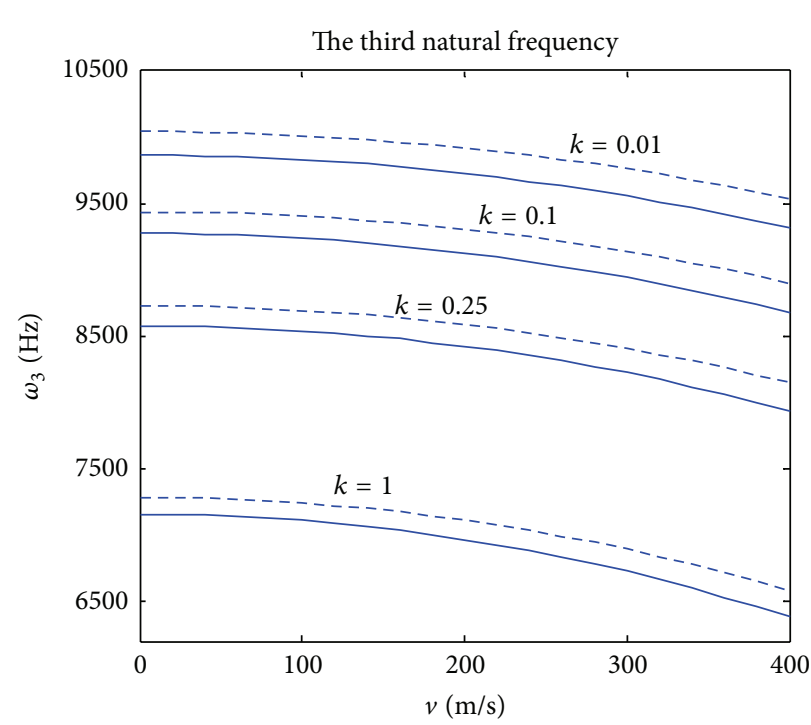

(c)

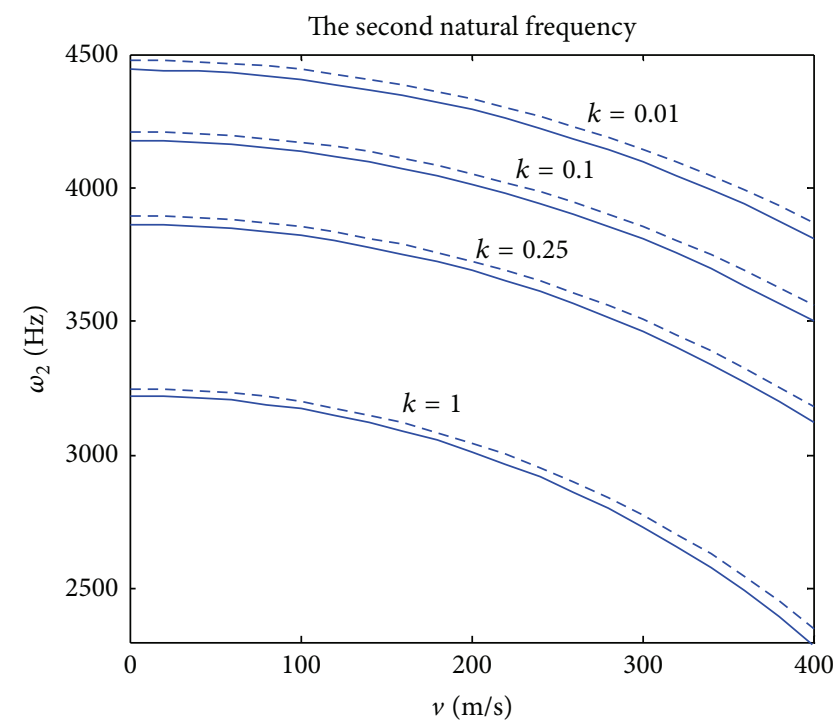

(b)

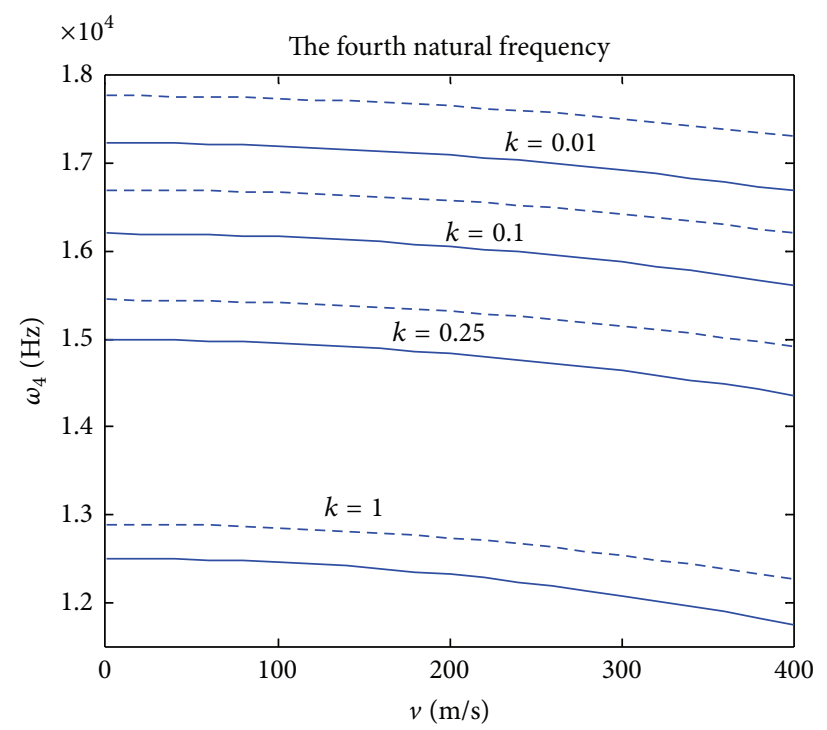

(d)

FiguRE 2: The natural frequencies versus axially moving speeds for different power-law exponents $\left(\sigma_{0}=1 \mathrm{MPa}\right)$.

Consider

$$
\begin{aligned}
& {\left[e^{\left(\beta_{1 n}+\beta_{2 n}\right)}+e^{\left(\beta_{3 n}+\beta_{4 n}\right)}\right]\left(\beta_{1 n}^{2}-\beta_{2 n}^{2}\right)\left(\beta_{3 n}^{2}-\beta_{4 n}^{2}\right)} \\
& \quad-\left[e^{\left(\beta_{1 n}+\beta_{3 n}\right)}+e^{\left(\beta_{2 n}+\beta_{4 n}\right)}\right]\left(\beta_{1 n}^{2}-\beta_{3 n}^{2}\right)\left(\beta_{2 n}^{2}-\beta_{4 n}^{2}\right) \\
& \quad+\left[e^{\left(\beta_{2 n}+\beta_{3 n}\right)}+e^{\left(\beta_{1 n}+\beta_{4 n}\right)}\right]\left(\beta_{2 n}^{2}-\beta_{3 n}^{2}\right)\left(\beta_{1 n}^{2}-\beta_{4 n}^{2}\right)=0 .
\end{aligned}
$$

Using (15) and (16), one can obtain the coefficients of (13); the expressions of $C_{2 n} \sim C_{4 n}$ are listed in Appendix B.
The $n$th modal function of the axially moving FGM beam is determined as

$$
\begin{aligned}
& \varphi_{n}(x) \\
& =\left\{e^{\beta_{1 n} x}-\frac{\left(\beta_{4 n}^{2}-\beta_{1 n}^{2}\right)\left(e^{\beta_{3 n}}-e^{\beta_{1 n}}\right)}{\left(\beta_{4 n}^{2}-\beta_{2 n}^{2}\right)\left(e^{\beta_{3 n}}-e^{\beta_{2 n}}\right)} e^{\beta_{2 n} x}\right. \\
& -\frac{\left(\beta_{4 n}^{2}-\beta_{1 n}^{2}\right)\left(e^{\beta_{2 n}}-e^{\beta_{1 n}}\right)}{\left(\beta_{4 n}^{2}-\beta_{3 n}^{2}\right)\left(e^{\beta_{2 n}}-e^{\beta_{3 n}}\right)} e^{\beta_{3 n} x} \\
& +\left(-1+\frac{\left(\beta_{4 n}^{2}-\beta_{1 n}^{2}\right)\left(e^{\beta_{3 n}}-e^{\beta_{1 n}}\right)}{\left(\beta_{4 n}^{2}-\beta_{2 n}^{2}\right)\left(e^{\beta_{3 n}}-e^{\beta_{2 n}}\right)}\right. \\
& \left.\left.+\frac{\left(\beta_{4 n}^{2}-\beta_{1 n}^{2}\right)\left(e^{\beta_{2 n}}-e^{\beta_{1 n}}\right)}{\left(\beta_{4 n}^{2}-\beta_{3 n}^{2}\right)\left(e^{\beta_{2 n}}-e^{\beta_{3 n}}\right)}\right) e^{\beta_{4 n} x}\right\} C_{1 n} .
\end{aligned}
$$




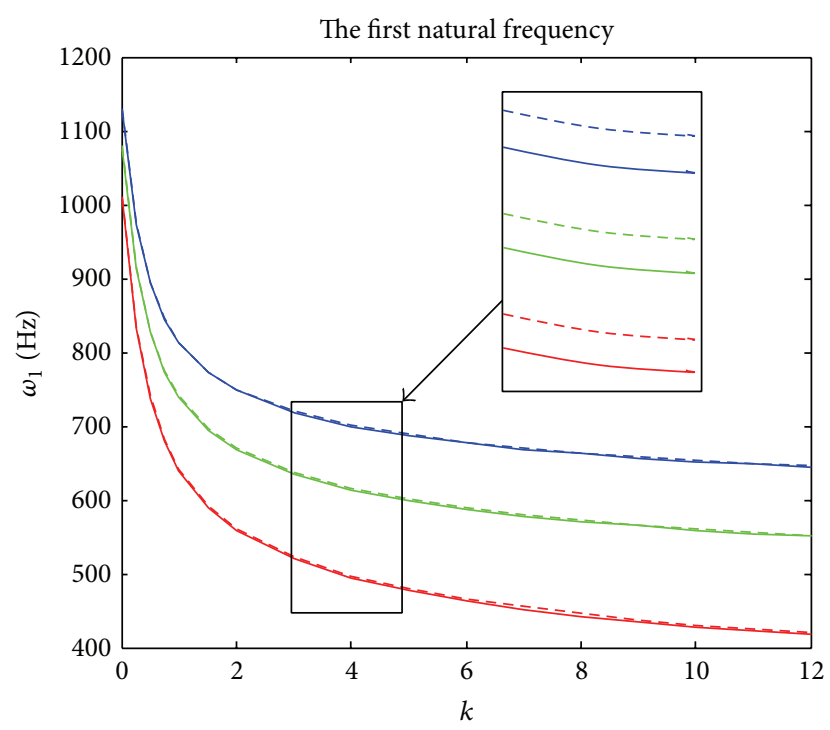

(a)

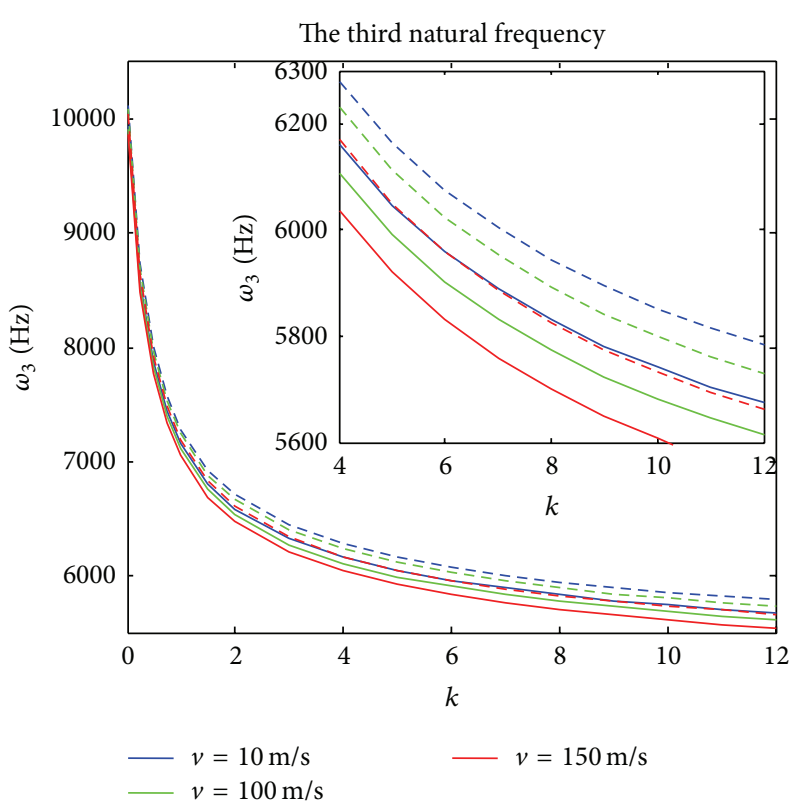

(c)

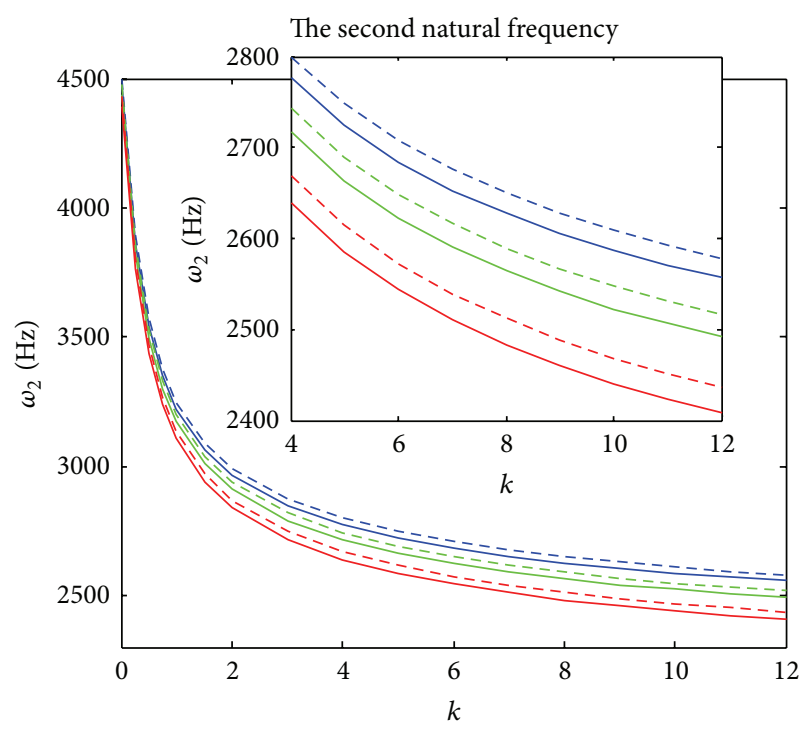

(b)

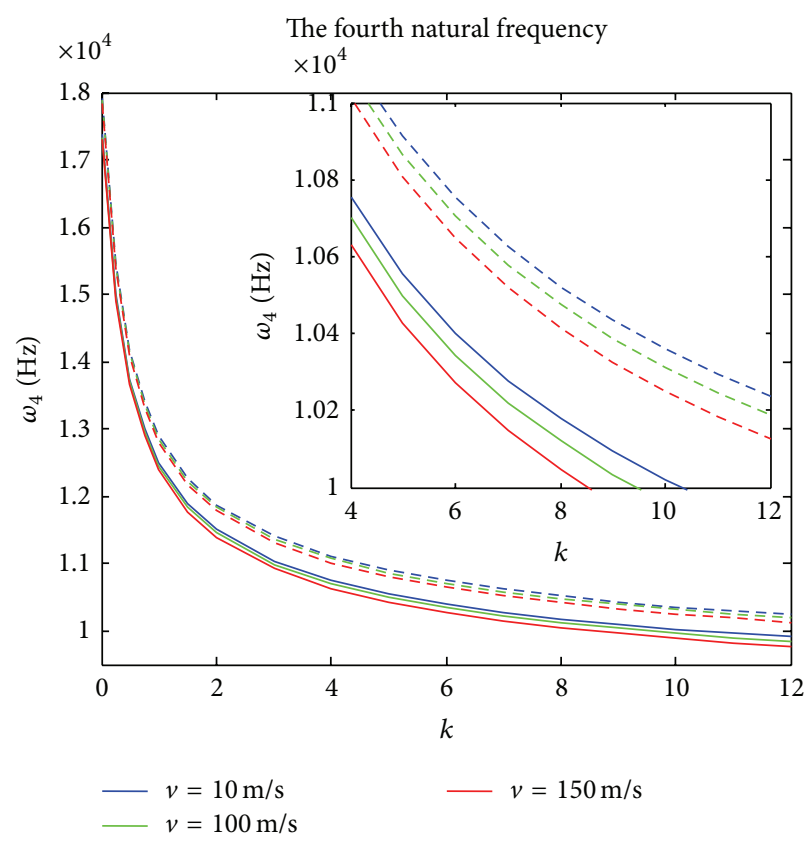

(d)

FIgURE 3: The natural frequencies versus power-law exponent for different axially moving speeds $\left(\sigma_{0}=1 \mathrm{MPa}\right)$.

4.2. Critical Speeds. The time-independent equilibrium form of the linear equation (7) can be written as

$$
\left(1-a_{2} v^{2}\right)\left(1+a_{4}-a_{1} v^{2}\right) \frac{\partial^{4} w}{\partial x^{4}}+a_{3}\left(a_{1} v^{2}-a_{4}\right) \frac{\partial^{2} w}{\partial x^{2}}=0
$$

The characteristic equation of (18) is

$$
\left(1-a_{2} v^{2}\right)\left(1+a_{4}-a_{1} v^{2}\right) r^{4}+a_{3}\left(a_{1} v^{2}-a_{4}\right) r^{2}=0 .
$$

When $v$ is higher than $100 \mathrm{~m} / \mathrm{s}$, numerical results demonstrate that $\left(1-a_{2} v^{2}\right)\left(1+a_{4}-a_{1} v^{2}\right)$ and $a_{3}\left(a_{1} v^{2}-a_{4}\right)$ are positive numbers. Consequently, the solution to (19) is determined as

$$
r_{1}=r_{2}=0, \quad r_{3}=r_{4}= \pm i \sqrt{\frac{a_{3}\left(a_{1} v^{2}-a_{4}\right)}{\left(1-a_{2} v^{2}\right)\left(1+a_{4}-a_{1} v^{2}\right)}} .
$$
by

On the other hand, the solution to (18) can be expressed

$$
w(x)=C_{1}+C_{2} x+C_{3} \cos (\beta x)+C_{4} \sin (\beta x),
$$




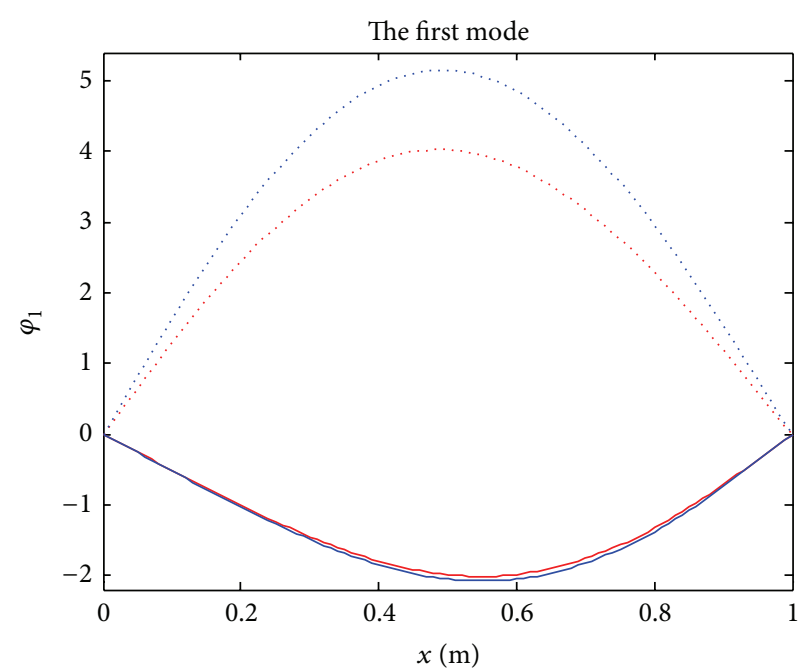

(a)

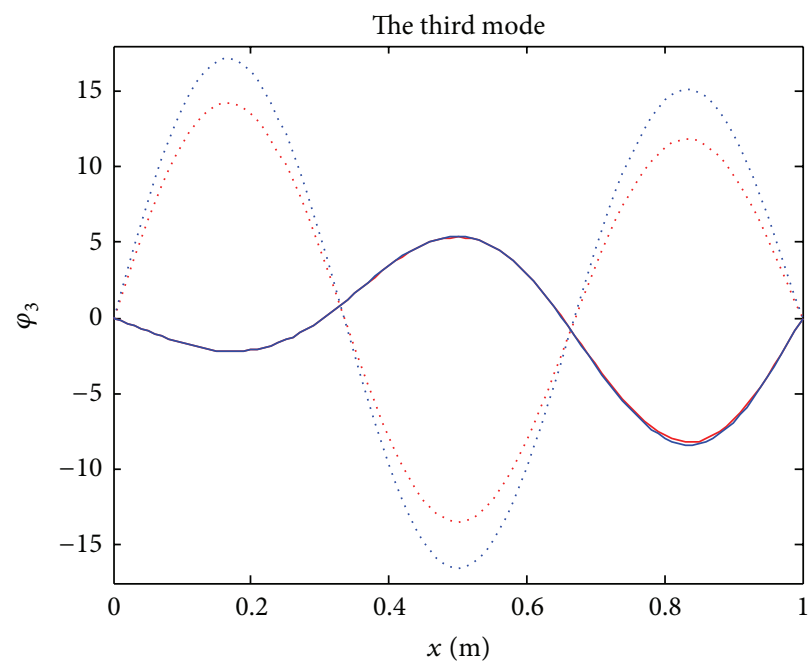

$-k=1$

$-k=0.25$

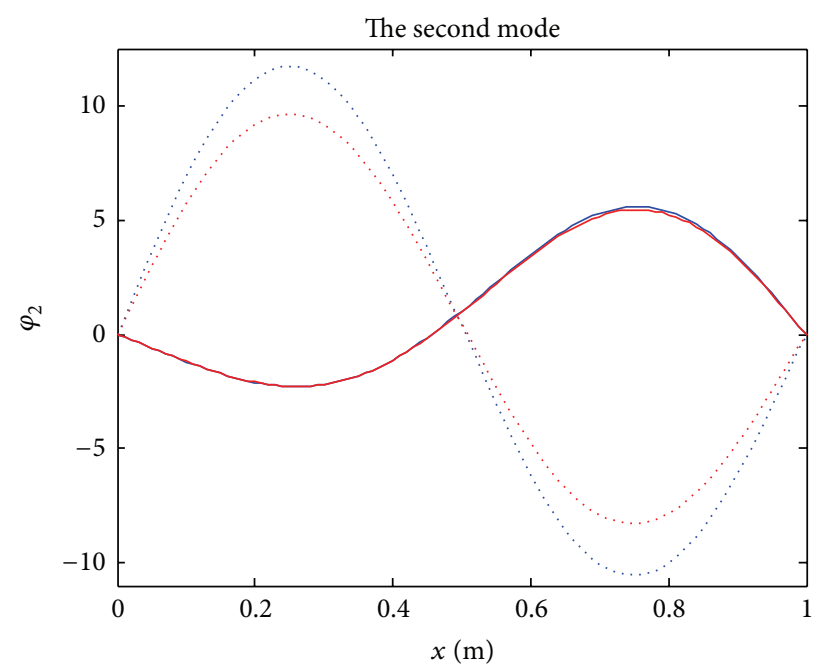

(b)

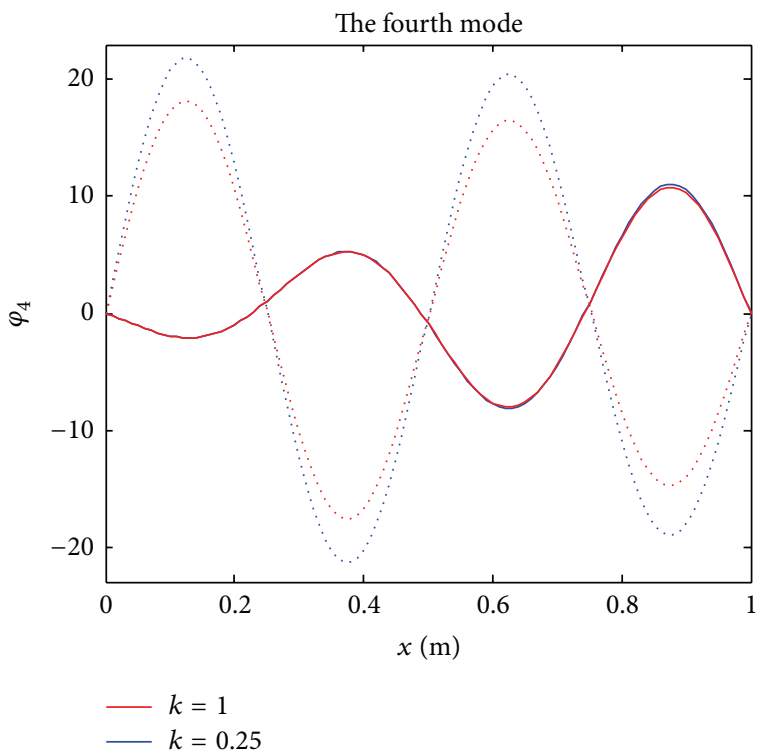

(d)

(c)

FIgURE 4: The first four modal functions ( $\left.v=100 \mathrm{~m} / \mathrm{s}, \sigma_{0}=1 \mathrm{MPa}\right)$.

where

$$
\beta=\sqrt{\frac{a_{3}\left(a_{1} v^{2}-a_{4}\right)}{\left(1-a_{2} v^{2}\right)\left(1+a_{4}-a_{1} v^{2}\right)}} .
$$

Substituting (21) into the boundary condition of (9) yields

$$
\left(\begin{array}{cccc}
1 & 0 & 1 & 0 \\
1 & L & \cos (\beta L) & \sin (\beta L) \\
0 & 0 & -\beta^{2} & 0 \\
0 & 0 & -\beta^{2} \cos (\beta L) & -\beta^{2} \sin (\beta L)
\end{array}\right)\left(\begin{array}{l}
C_{1} \\
C_{2} \\
C_{3} \\
C_{4}
\end{array}\right)=0 .
$$

For the nontrivial solution of (23), the determinant of the coefficient matrix must be zero, which results in

$$
L \beta^{4} \sin (L \beta)=0 .
$$

Using (22) and (24), as well as the conditions $\beta L=n \pi$ and $n=1$, one can get the critical speeds of axially moving FGM beam as follows:

$$
v_{c}=\sqrt{\frac{M-N}{2 \pi^{2} a_{1} a_{2}}}
$$

or

$$
v_{c}=\sqrt{\frac{M+N}{2 \pi^{2} a_{1} a_{2}}},
$$

where

$$
\begin{aligned}
M= & \pi^{2}\left(a_{1}+a_{2}+a_{2} a_{4}\right)+L^{2} a_{1} a_{3}, \\
N= & \left(\left(a_{1}\left(\pi^{2}+L^{2} a_{3}\right)+\pi^{2} a_{2}\left(1+a_{4}\right)\right)^{2}\right. \\
& \left.\quad-4 \pi^{2} a_{1} a_{2}\left(\pi^{2}+\pi^{2} a_{4}+L^{2} a_{3} a_{4}\right)\right)^{1 / 2} .
\end{aligned}
$$




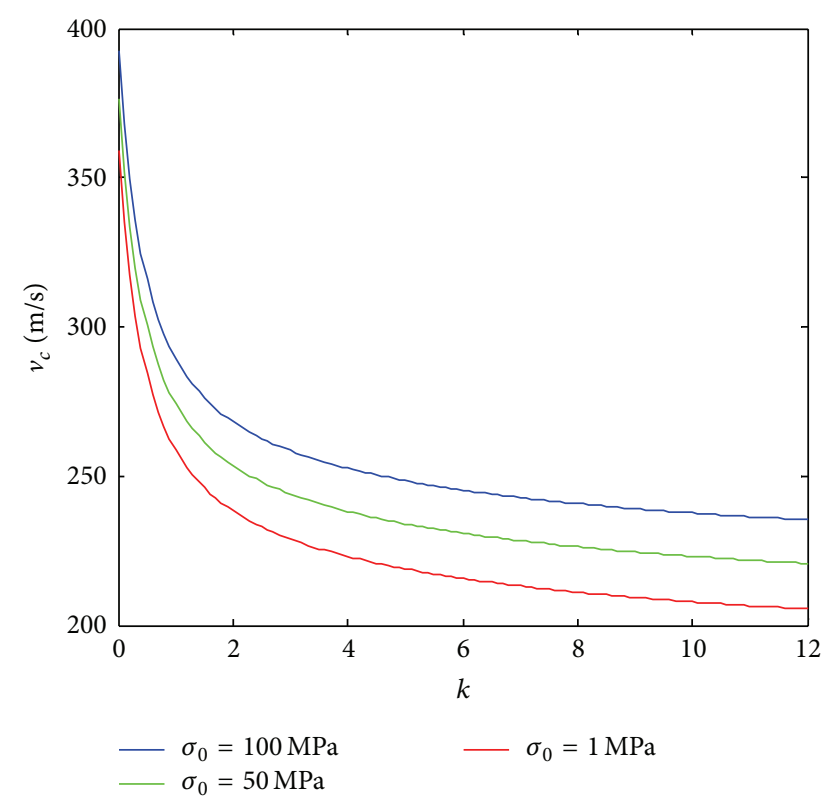

FIGURE 5: The critical speeds versus power-law exponent for different initial stress.

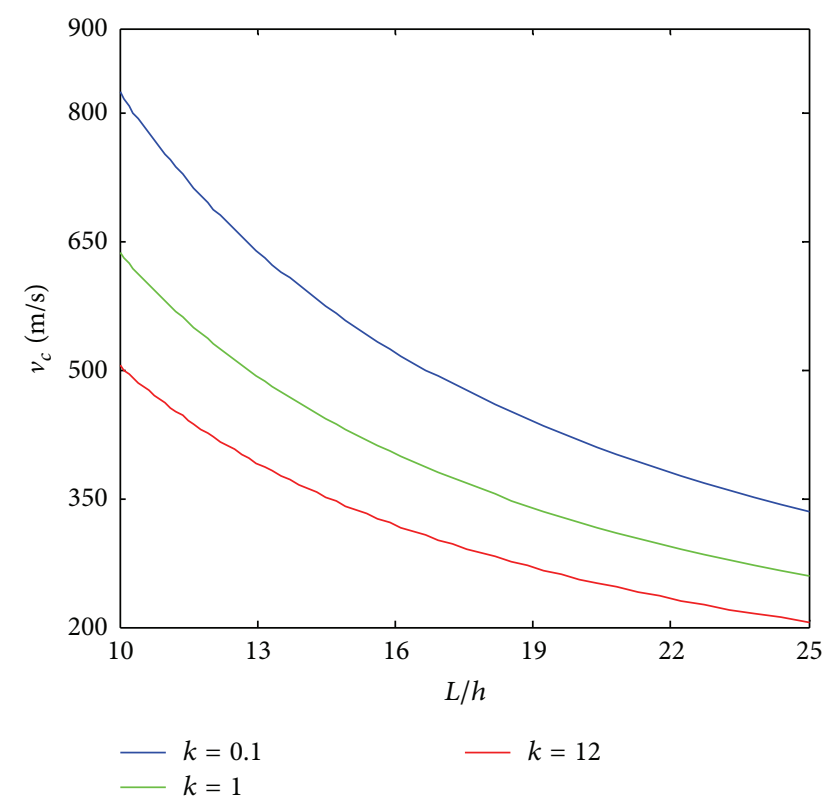

FIGURE 6: The critical speeds versus $L / h$ ratio for different power-law exponents $\left(\sigma_{0}=1 \mathrm{MPa}\right)$.

Combined with numerical results in Section 4.3, it can be verified that the critical speed can be determined by equation (25) only.

4.3. Numerical Results and Discussions. In the following numerical computation, the beam is made of steel metal and Alumina ceramics; several parameters are chosen to be

$$
\begin{gathered}
L=1 \mathrm{~m}, \quad h=0.04 \mathrm{~m}, \quad b=0.04 \mathrm{~m}, \quad \mu=0.3, \\
\kappa=\frac{5}{6} .
\end{gathered}
$$

TABLE 1: Effect of initial stress on first four frequencies for FGM beam $(v=100 \mathrm{~m} / \mathrm{s})$.

\begin{tabular}{cccccc}
\hline$k$ & $\sigma_{0}(\mathrm{MPa})$ & $\omega_{1}(\mathrm{~Hz})$ & $\omega_{2}(\mathrm{~Hz})$ & $\omega_{3}(\mathrm{~Hz})$ & $\omega_{4}(\mathrm{~Hz})$ \\
\hline \multirow{4}{*}{0.001} & 1 & 1075 & 4436 & 9900 & 17322 \\
& 50 & 1129 & 4490 & 9955 & 17377 \\
& 100 & 1182 & 4545 & 10010 & 17433 \\
& Increase rate & $9.95 \%$ & $2.46 \%$ & $1.11 \%$ & $0.64 \%$ \\
\hline \multirow{4}{*}{1} & 1 & 738 & 3170 & 7109 & 12455 \\
& 50 & 790 & 3221 & 7160 & 12506 \\
& 100 & 841 & 3272 & 7211 & 12559 \\
& Increase rate & $13.96 \%$ & $3.22 \%$ & $1.43 \%$ & $0.84 \%$ \\
\hline \multirow{4}{*}{100} & 1 & 496 & 2304 & 5209 & 9147 \\
& 50 & 553 & 2357 & 5262 & 9200 \\
& 100 & 605 & 2409 & 5315 & 9254 \\
& Increase rate & $21.98 \%$ & $4.56 \%$ & $2.03 \%$ & $1.17 \%$ \\
\hline
\end{tabular}

Natural frequencies are found by numerically solving (11) and (16), simultaneously, with different speeds, different power-law exponents, and different initial stresses. Figure 2 illustrates the effect of axial speed on the first four natural frequencies for different power-law exponents. As observed, with the increase of axially moving speed, natural frequencies decrease. Increasing the power-law exponent on the other hand causes a decrease in natural frequencies. Figure 3 illustrates the effect of power-law exponents on the first four natural frequencies under different axially moving speeds. As observed, with the increase of power-law exponent, natural frequencies decrease, and the decrease becomes more and more gentle.

In Figures 2 and 3 the solid lines and dashed lines denote the Timoshenko model and the Euler beam model, respectively. The frequencies are lower with Timoshenko model comparing with the Euler model, as other parameters are fixed. Besides, the numerical results demonstrate that the difference of the natural frequencies with the two models becomes more significant as the order increases.

The frequencies of a FGM beam always remain between the frequencies of its constituent material of the beam; that is, when $k$ is small, the content of ceramic in the beam is high; then the natural frequencies of FGM beams are close to the natural frequencies of the pure ceramic beam. When $k$ is large, the content of metal in the beam is high, and the natural frequencies of FGM beams approach the natural frequencies of the pure metal beam.

Table 1 shows the first four natural frequencies with different $\sigma_{0}$ and different $k$. It is seen that natural frequencies are increasing with increasing $\sigma_{0}$ and decreasing with an increase in $k$. Moreover, with the increase of $k$, the increase rate of each order raises to some extent and the first frequencies raise the most.

After obtaining the natural frequencies of the system, the solution $\beta_{1 n} \sim \beta_{4 n}$ of (11) can be obtained. Subsequently, using (17), one can get the modal function of the axially moving FGM beam. Figure 4 presents the first four modal functions, in which the solid lines and dashed lines denote the real and 
imaginary parts of the modal functions, respectively, where $v=100 \mathrm{~m} / \mathrm{s}$ and $\sigma_{0}=1 \mathrm{MPa}$ are adopted.

With an increase of axially moving speed, each order of the frequency tends to vanish. The exact values at which the first natural frequency vanishes are called the critical speeds. If axially moving speed is higher than the critical speed, the system is unstable. Figure 5 illustrates the effect of $k$ on the critical speeds for different initial stress. The numerical results indicate that the critical speeds of the beam decrease with the increasing $k$ and the decreasing $\sigma_{0}$. For a specific initial stress, for example, $\sigma_{0}=1 \mathrm{MPa}$, with an increase of $k$, the critical speeds begin to decrease rapidly and then gently. The effects of the $L / h$ ratio on the critical speeds for different $k$ are shown in Figure 6. The larger $L / h$ ratio leads to lower critical speeds for given $k$ and the higher the critical speeds the smaller the $k$ for given $L / h$ ratio.

\section{Conclusions}

This work is devoted to the transverse dynamic responses of axially moving, initially tensioned Timoshenko beams made of FGM. The complex mode approach is performed to obtain the natural frequencies and modal functions, respectively. The effects of some parameters including axially moving speed and the power-law exponent on the natural frequencies are investigated. Some numerical examples are presented to demonstrate the comparisons of natural frequencies for Timoshenko beam model and Euler beam model. The critical speeds are determined and numerically investigated. The results show that an increase of the power-law exponent or the axial speed results in a lower natural frequency, while the axial initial stress tends to increase the natural frequencies. With the increase of the power-law exponent or the $L / h$ ratio, the critical speeds decrease, while the axial initial stress tends to increase the critical speeds. The results reported in this work could be useful for designing and optimizing the axially moving FGM Timoshenko beam-like structures.

\section{Appendices}

\section{A. Result of Substituting (2) into (4) Leads to}

Consider

$$
\begin{gathered}
\int_{t_{1}}^{t_{2}} \int_{0}^{L}\left[\kappa G_{T}\left(\frac{\partial^{2} w}{\partial x^{2}}-\frac{\partial \psi}{\partial x}\right)\right. \\
-\rho_{T 0}\left(\frac{\partial^{2} w}{\partial t^{2}}+2 v \frac{\partial^{2} w}{\partial t \partial x}+v^{2} \frac{\partial^{2} w}{\partial x^{2}}\right) \\
\left.+\sigma_{0} A \frac{\partial^{2} w}{\partial x^{2}}\right] \delta w d x d t \\
+\int_{t_{1}}^{t_{2}} \int_{0}^{L}\left[(E I)_{\mathrm{eq}} \frac{\partial^{2} \psi}{\partial x^{2}}-\rho_{T 2}\left(\frac{\partial^{2} \psi}{\partial t^{2}}+2 v \frac{\partial^{2} \psi}{\partial t \partial x}+v^{2} \frac{\partial^{2} \psi}{\partial x^{2}}\right)\right. \\
\left.+\kappa G_{T}\left(\frac{\partial w}{\partial x}-\psi\right)\right] \delta \psi d x d t
\end{gathered}
$$

$$
\begin{aligned}
& +\left.\rho_{T 0} \int_{t_{1}}^{t_{2}} \int\left(v \frac{\partial w}{\partial t} \delta w+v^{2} \frac{\partial w}{\partial x} \delta w\right)\right|_{0} ^{L} d t \\
& +\left.\rho_{T 0} \int_{0}^{L}\left(\frac{\partial w}{\partial t} \delta w+v \frac{\partial w}{\partial x} \delta w\right)\right|_{t_{1}} ^{t_{2}} d x \\
& +\left.\rho_{T 2} \int_{t_{1}}^{t_{2}}\left(v \frac{\partial \psi}{\partial t} \delta \psi+v^{2} \frac{\partial \psi}{\partial x} \delta \psi\right)\right|_{0} ^{L} d t \\
& +\left.\rho_{T 2} \int_{0}^{L}\left(\frac{\partial \psi}{\partial t} \delta \psi+v \frac{\partial \psi}{\partial x} \delta \psi\right)\right|_{t_{1}} ^{t_{2}} d x \\
& -\left.\kappa G_{T} \int_{t_{1}}^{t_{2}}\left(\frac{\partial w}{\partial x} \delta w+\psi \delta w\right)\right|_{0} ^{L} d t-\left.\sigma_{0} A \int_{t_{1}}^{t_{2}} \frac{\partial w}{\partial x} \delta w\right|_{0} ^{L} d t \\
& -\left.(E I)_{\mathrm{eq}} \int_{t_{1}}^{t_{2}} \frac{\partial \psi}{\partial x} \delta \psi\right|_{0} ^{L} d t=0 .
\end{aligned}
$$

\section{B. The Coefficient of (13)}

Consider

$$
\begin{aligned}
C_{2 n}= & -\frac{\left(\beta_{4 n}^{2}-\beta_{1 n}^{2}\right)\left(e^{\beta_{3 n}}-e^{\beta_{1 n}}\right)}{\left(\beta_{4 n}^{2}-\beta_{2 n}^{2}\right)\left(e^{\beta_{3 n}}-e^{\beta_{2 n}}\right)} C_{1 n} \\
C_{3 n}= & -\frac{\left(\beta_{4 n}^{2}-\beta_{1 n}^{2}\right)\left(e^{\beta_{2 n}}-e^{\beta_{1 n}}\right)}{\left(\beta_{4 n}^{2}-\beta_{3 n}^{2}\right)\left(e^{\beta_{2 n}}-e^{\beta_{3 n}}\right)} C_{1 n} \\
C_{4 n}= & {\left[-1+\frac{\left(\beta_{4 n}^{2}-\beta_{1 n}^{2}\right)\left(e^{\beta_{3 n}}-e^{\beta_{1 n}}\right)}{\left(\beta_{4 n}^{2}-\beta_{2 n}^{2}\right)\left(e^{\beta_{3 n}}-e^{\beta_{2 n}}\right)}\right.} \\
& \left.+\frac{\left(\beta_{4 n}^{2}-\beta_{1 n}^{2}\right)\left(e^{\beta_{2 n}}-e^{\beta_{1 n}}\right)}{\left(\beta_{4 n}^{2}-\beta_{3 n}^{2}\right)\left(e^{\beta_{2 n}}-e^{\beta_{3 n}}\right)}\right] C_{1 n} .
\end{aligned}
$$

\section{Conflict of Interests}

The authors declare that there is no conflict of interests regarding the publication of this paper.

\section{Acknowledgments}

This work was supported by National Natural Science Foundation of China (nos. 11202145, 51405321), the Jiangsu Provincial Natural Science Foundation of China (no. BK2012175), and the Natural Science Foundation of the Jiangsu Higher Education Institutions of China (no. 14KJB460026).

\section{References}

[1] H. R. Öz, "Natural frequencies of axially travelling tensioned beams in contact with a stationary mass," Journal of Sound and Vibration, vol. 259, no. 2, pp. 445-456, 2003.

[2] L.-Q. Chen, X.-D. Yang, and C.-J. Cheng, "Dynamic stability of an axially accelerating viscoelastic beam," European Journal of Mechanics-A/Solids, vol. 23, no. 4, pp. 659-666, 2004. 
[3] L. Q. Chen and X. D. Yang, "Steady-state response of axially moving viscoelastic beams with pulsating speed: comparison of two nonlinear models," International Journal of Solids and Structures, vol. 42, no. 1, pp. 37-50, 2005.

[4] L.-Q. Chen and X.-D. Yang, "Vibration and stability of an axially moving viscoelastic beam with hybrid supports," European Journal of Mechanics A: Solids, vol. 25, no. 6, pp. 996-1008, 2006.

[5] U. Lee and I. Jang, "On the boundary conditions for axially moving beams," Journal of Sound and Vibration, vol. 306, no. 3-5, pp. 675-690, 2007.

[6] W. Lin and N. Qiao, "Vibration and stability of an axially moving beam immersed in fluid," International Journal of Solids and Structures, vol. 45, no. 5, pp. 1445-1457, 2008.

[7] M. H. Ghayesh, F. Alijani, and M. A. Darabi, "An analytical solution for nonlinear dynamics of a viscoelastic beam-heavy mass system," Journal of Mechanical Science and Technology, vol. 25, no. 8, pp. 1915-1923, 2011.

[8] H. Lv, Y. Li, L. Li, and Q. Liu, "Transverse vibration of viscoelastic sandwich beam with time-dependent axial tension and axially varying moving velocity,' Applied Mathematical Modelling, vol. 38, no. 9-10, pp. 2558-2585, 2014.

[9] U. Lee, J. Kim, and H. Oh, "Spectral analysis for the transverse vibration of an axially moving Timoshenko beam," Journal of Sound and Vibration, vol. 271, no. 3-4, pp. 685-703, 2004.

[10] Y.-Q. Tang, L.-Q. Chen, and X.-D. Yang, "Parametric resonance of axially moving Timoshenko beams with time-dependent speed," Nonlinear Dynamics, vol. 58, no. 4, pp. 715-724, 2009.

[11] M. H. Ghayesh and S. Balar, "Non-linear parametric vibration and stability analysis for two dynamic models of axially moving Timoshenko beams," Applied Mathematical Modelling, vol. 34, no. 10, pp. 2850-2859, 2010.

[12] B. Li, Y. Tang, and L. Chen, "Nonlinear free transverse vibrations of axially moving Timoshenko beams with two free ends," Science China Technological Sciences, vol. 54, no. 8, pp. 19661976, 2011.

[13] M. H. Ghayesh and M. Amabili, "Nonlinear vibrations and stability of an axially moving Timoshenko beam with an intermediate spring support," Mechanism and Machine Theory, vol. 67, pp. 1-16, 2013.

[14] H. J. Ding, D. J. Huang, and W. Q. Chen, "Elasticity solutions for plane anisotropic functionally graded beams," International Journal of Solids and Structures, vol. 44, no. 1, pp. 176-196, 2007.

[15] Y.-A. Kang and X.-F. Li, "Bending of functionally graded cantilever beam with power-law non-linearity subjected to an end force," International Journal of Non-Linear Mechanics, vol. 44, no. 6, pp. 696-703, 2009.

[16] F.-X. Zhou, S.-R. Li, Y.-M. Lai, and Y. Yang, "Analyzing of functionally graded materials by discrete element method," Applied Mechanics and Materials, vol. 29-32, pp. 1948-1953, 2010.

[17] M. Şimşek, "Vibration analysis of a functionally graded beam under a moving mass by using different beam theories," Composite Structures, vol. 92, no. 4, pp. 904-917, 2010.

[18] A. E. Alshorbagy, M. A. Eltaher, and F. F. Mahmoud, "Free vibration characteristics of a functionally graded beam by finite element method," Applied Mathematical Modelling, vol. 35, no. 1, pp. 412-425, 2011.

[19] L. L. Ke, Y. S. Wang, J. Yang, and S. Kitipornchai, "Nonlinear free vibration of size-dependent functionally graded microbeams," International Journal of Engineering Science, vol. 50, no. 1, pp. 256-267, 2012.
[20] M. Şimşek, T. Kocatürk, and Ș. D. Akbaş, "Static bending of a functionally graded microscale Timoshenko beam based on the modified couple stress theory," Composite Structures, vol. 95, pp. 740-747, 2013. 


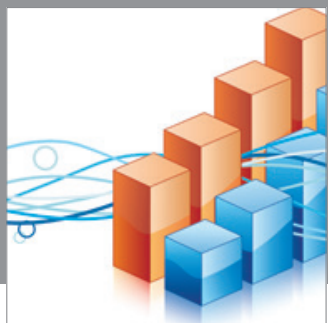

Advances in

Operations Research

mansans

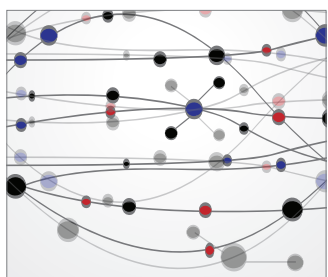

The Scientific World Journal
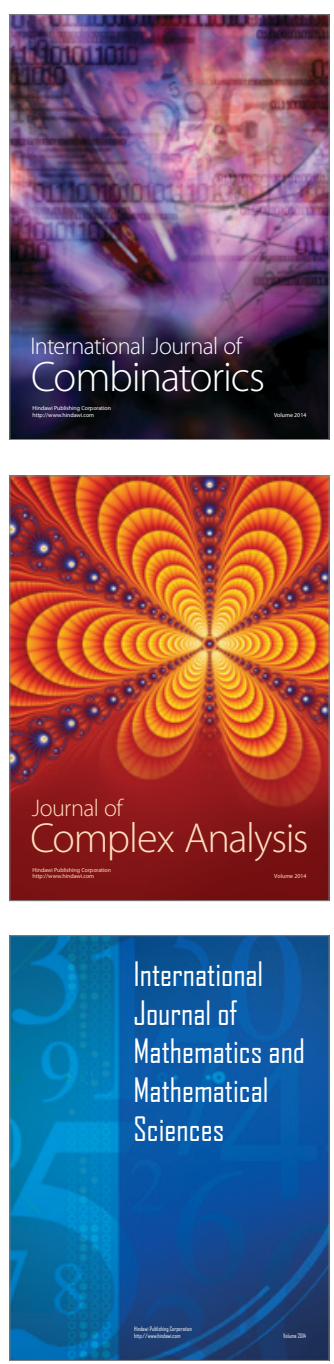
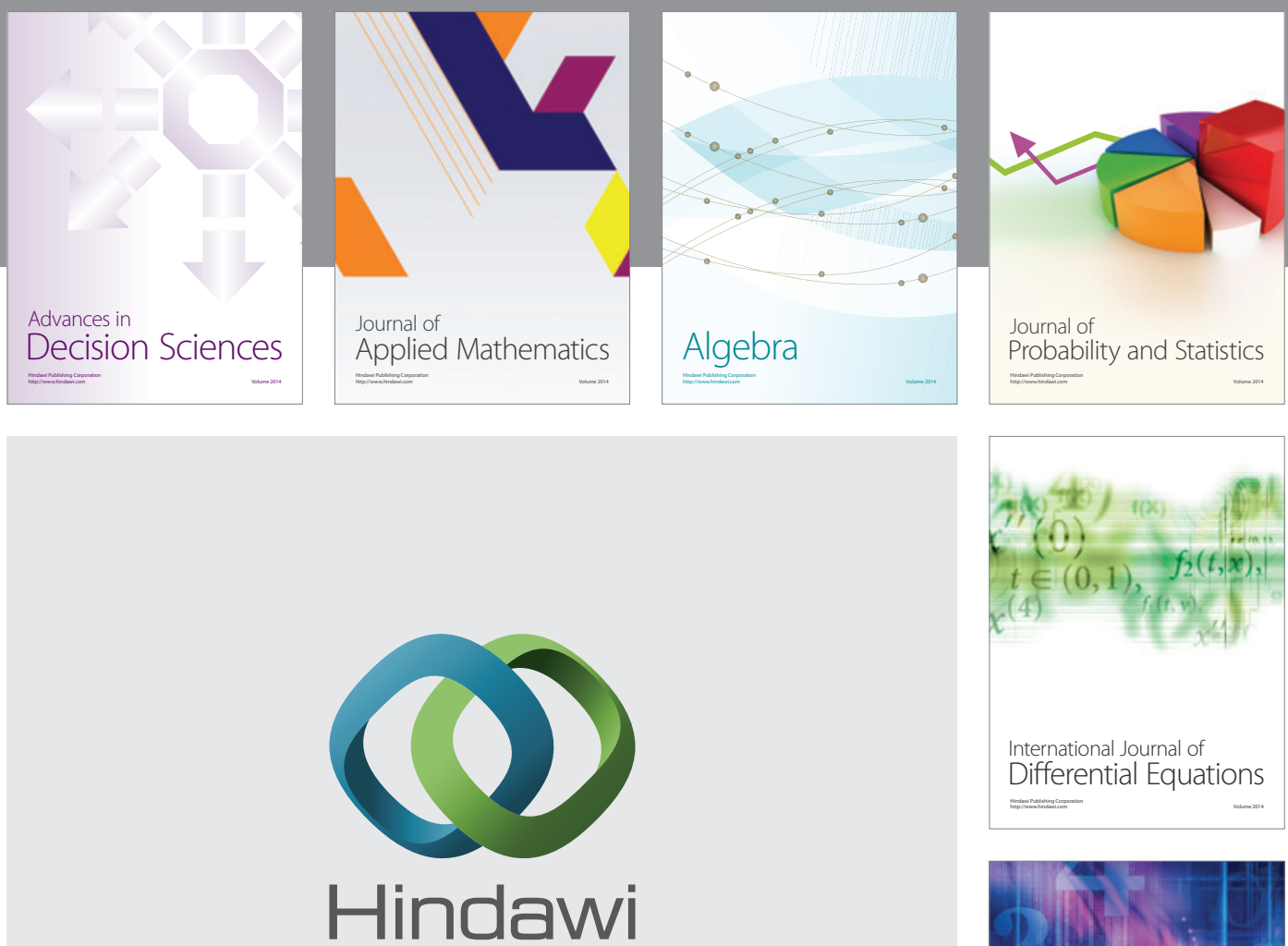

Submit your manuscripts at http://www.hindawi.com
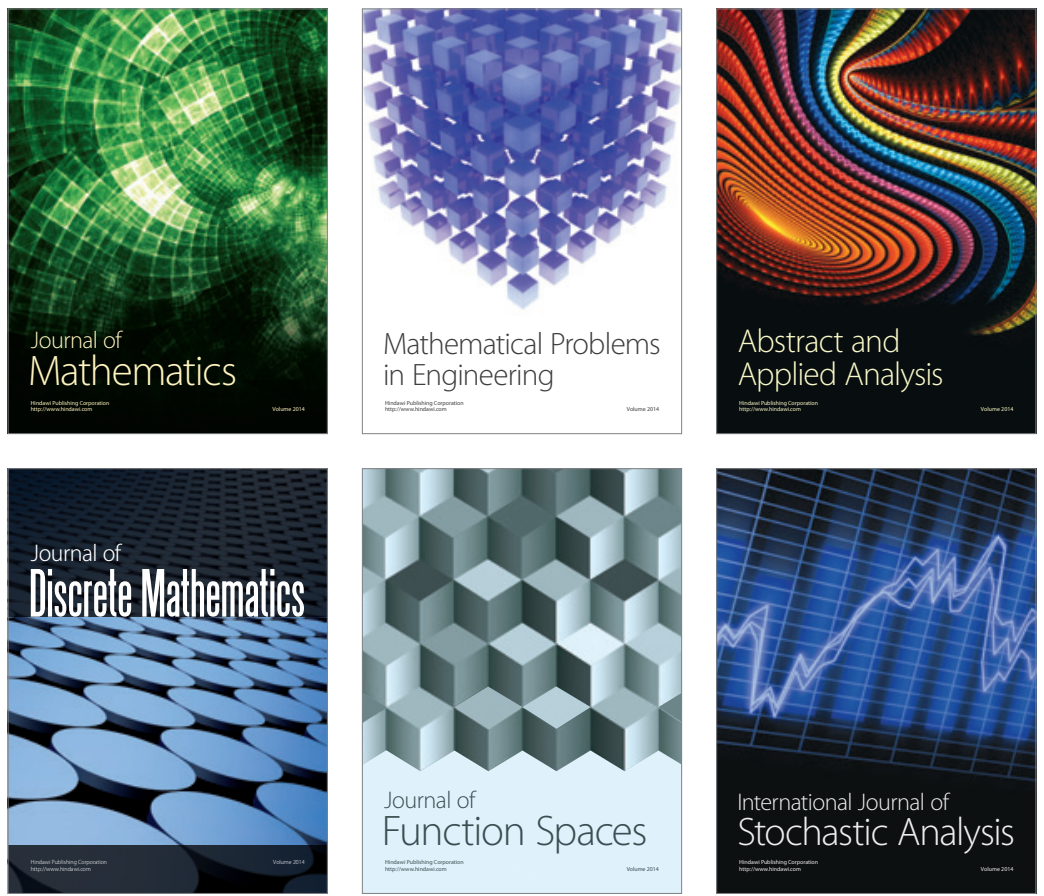

Journal of

Function Spaces

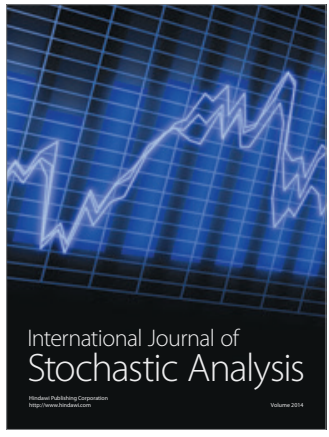

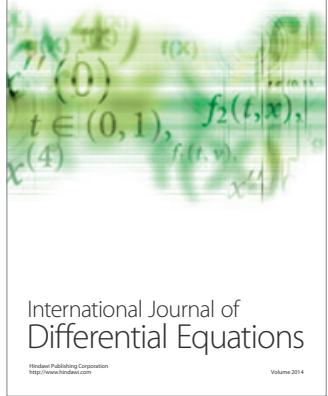
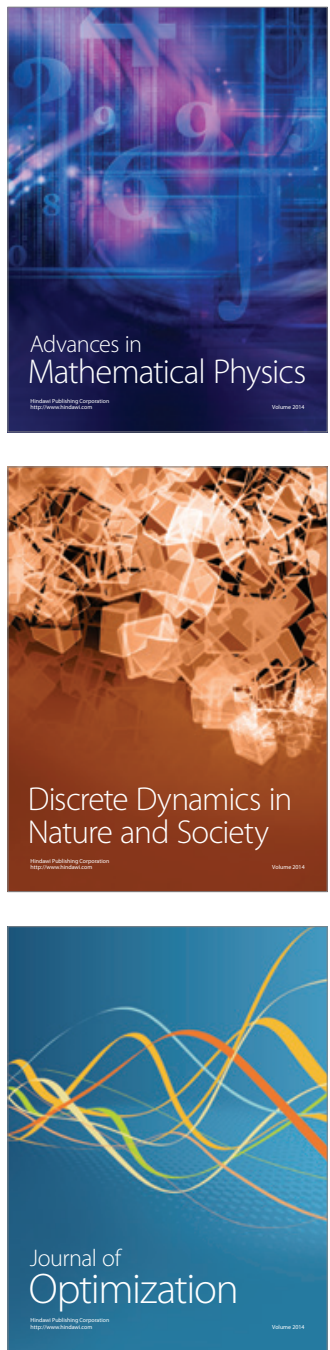